\title{
O processo de escolarização entre os Xakriabá: explorando alternativas de análise na antropologia da educação
}

\author{
Ana Maria R. Gomes
}

Universidade Federal de Minas Gerais, Faculdade de Educação
A criação das escolas estaduais indígenas pelo Programa de Implantação das Escolas Indígenas de Minas Gerais (PIEI-MG), em 1997, foi um fato marcante para todos os povos envolvidos: Maxakali, Pataxó, Krenak e Xakriabá. A configuração das escolas seguiu as orientações legais previstas em âmbito nacional - que garantem o direito à educação diferenciada e estabelecem seus parâmetros de funcionamento - e deu origem a formas específicas de organização institucional e de condução das atividades didáticas, em função das exigências e das características de cada povo indígena. ${ }^{1}$

Entre os Xakriabá, no entanto, o processo de escolarização teve seu início pelo menos sessenta anos antes da criação das escolas indígenas, em época que antecede o reconhecimento, por parte da Fundação Nacional do Índio (FUNAI), da existência da

1 Faz-se referência ao texto da Constituição Federal de 1988, à Lei de Diretrizes e Bases da Educação Nacional (LDBEN) de 1996 e ao Referencial Curricular Nacional para as Escolas Indígenas (RCNEI), de 1998. população indígena local, ao final dos anos de 1970, e a demarcação do seu território, cuja homologação se deu somente em 1987. Em todo esse período, as possibilidades de acesso à instrução foram crescendo de modo progressivo e lento, fruto de uma luta incessante pela escola por pelo menos parte da população local.

Os dados disponíveis permitiram verificar que, embora iniciado anos antes, o processo de escolarização entre os Xakriabá foi intensificado de modo muito acelerado com o início do funcionamento das escolas estaduais indígenas. Em pouco mais de dois anos, os Xakriabá passaram, de uma oferta escolar que atendia a menos da metade da demanda, a apresentar um quadro semelhante à oferta em Minas Gerais, que garante vagas para quase a totalidade das crianças e adolescentes em idade de cursar o ensino fundamental. Tal expansão acelerada gerou um contexto escolar com características muito peculiares, além de provocar profundas mudanças na vida das comunidades, nas dimensões econômica, social, política e cultural (Gomes, 2003a). A continuidade dessa expansão é bem presente, com reivindicação de 
abertura de outras modalidades de ensino (educação infantil e educação de jovens e adultos), além da proposta de criação do ensino médio e de acesso à universidade. É marcante a forma incisiva com que os próprios Xakriabá implementam a expansão da escolarização, sem que se tenha, no momento, uma análise mais clara das implicações de um processo conduzido com tal rapidez.

É dentro desse quadro que busco explorar algumas perspectivas de análise sobre os processos de escolarização, propostas pela antropologia da educação, retomando o recorte conceitual que caracteriza cada abordagem. Particularmente, busco explorar o debate que se instituiu sobre o tema do desempenho escolar das minorias étnicas nos Estados Unidos, ${ }^{2}$ dentro do qual se configuraram duas posições teóricometodológicas: a das descontinuidades culturais e a do modelo ecológico cultural. ${ }^{3}$

Neste artigo, proponho-me a retomar os termos do debate teórico e identificar as orientações das duas posições, confrontando-as com as questões que a pesquisa sobre a escolarização dos Xakriabá têm suscitado. Esse exercício analítico parece-me adequado para a explicitação de problemas e dificuldades recorrentes tanto na descrição e análise dos processos de escolarização dos grupos étnicos minoritários (ou, em outros termos, do sucesso/insucesso escolar desses grupos) quanto nas implicações para as propostas de intervenção pedagógica e para a formulação de políticas públicas.

2 Tal debate tem início ao final dos anos de 1970 e desenvolve-se até os anos de 1990, passando por um período de maior acirramento das posições no curso dos anos de 1980. Ver Jacob e Jordan (1987) e Gibson (1997), para uma apresentação inicial do debate.

3 Para um confronto entre abordagens teóricas sobre os processos de escolarização na história da educação, ver Gomes (2003b); para uma discussão das interfaces da escolarização com a dimensão econômico-produtiva, ver Lenzi-Grillini, Castro e Gomes (2004).

\section{O desempenho escolar das minorias étnicas: recuperando os termos de um debate}

Os estudos que levaram ao aparecimento da antropologia da educação como setor acadêmico nos Estados Unidos alcançaram seu ponto alto no início dos anos de $1970^{4}$ e tiveram como estímulo determinante a necessidade de contrapor-se ao modelo explicativo prevalente na época sobre os problemas de escolarização das minorias étnicas, ou seja, contrapor-se ao modelo da privação cultural, à noção de déficit cultural e aos desdobramentos em termos de uma pedagogia compensatória. Até então, os estudos realizados no campo antropológico sobre as dinâmicas familiares e comunitárias de socialização, que se desenvolveram de modo particular dentro da corrente conhecida como "cultura e personalidade", realizavam-se principalmente em sociedades em que a escola não estava ainda presente, ou era interpretada como uma instituição pouco significativa por parte dos pesquisadores. ${ }^{5}$

Uma das marcas importantes da entrada da antropologia no estudo da escola foi justamente a ampliação do foco das pesquisas, ao não tomar a instrução escolar como único contexto educativo, e sim como uma parte do processo mais amplo, e que, por-

4 Em 1970 foi criado o Council of Anthropology and Education (CAE), dentro da American Anthropology Association (AAA), e em 1978 o boletim do CAE transformou-se na revista Anthropology and Education Quarterly.

5 É interessante notar que nesse período, embora a atuação dos antropólogos norte-americanos na sua própria sociedade fosse voltada para a melhoria da educação escolar das minorias, dos imigrados e das classes sociais desfavorecidas, os estudos existentes traziam uma escassa discussão teórica sobre a questão educacional (Ogbu, 1996, p. 6). Um quadro semelhante ao indicado por Silva (2001) quanto à possível emergência do campo da antropologia da educação no Brasil. Em outras palavras, em ambos os casos o empenho político pela melhoria das condições da educação escolar em sua fase inicial não se fez acompanhar de uma discussão teórica suficientemente estruturada. 
tanto, deveria ser estudada em conexão com as demais instituições e processos que constituem as dinâmicas educativas dos diferentes grupos sociais. Um segundo elemento central foi a introdução da categoria das diferenças culturais para contrapor-se à noção de deficiência, deslocando duplamente o eixo conceitual da discussão: das dificuldades dos sujeitos individuais para o campo das diferenças coletivas na forma de viver e interpretar a experiência social.

Nesse contexto de discussão é que emerge a abordagem conhecida como "descontinuidades culturais" (ou conflito cultural), que enfatizava as diferenças entre as orientações culturais vivenciadas pelos alunos nas suas comunidades, no seu contexto de vida cotidiana, e as orientações que estruturavam as relações sociais e as atividades didáticas desenvolvidas na escola. Segundo essa abordagem, seriam exatamente as descontinuidades entre diferentes modelos culturais - ou o conflito entre eles - que levariam os alunos pertencentes aos grupos minoritários a encontrar barreiras para alcançar um êxito positivo no seu percurso escolar. ${ }^{6}$

Duas grandes linhas de pesquisa desenvolveramse a partir do tema do desempenho escolar das minorias, nessa nova perspectiva. Como uma das referências emblemáticas da primeira linha, podemos citar a pesquisa de Philips (1993), The invisible culture. Philips estudou as diferentes estruturas de participação nas interações, observando as diferenças entre o modelo que regulava as interações entre professores e alunos na escola e o modelo que regulava as intera-

6 Seguimos aqui a sugestão de Emihovich (1996), que, a partir do tema mais amplo indicado como "Continuidade e descontinuidade cultural em educação", faz referência a quatro diferentes perspectivas teóricas: a abordagem baseada na continuidade/descontinuidade cultural; a abordagem das descontinuidades culturais secundárias; a teoria da reprodução cultural; e a abordagem baseada em cultura e cognição. Como outras sínteses que apresentam essas diferentes posições, ver Rockwell (1992) e, particularmente para as duas primeiras, que serão objeto de discussão neste trabalho, ver Poveda (2001). ções na reserva indígena de Warm Springs. Philips observou, na vida cotidiana da aldeia indígena, a ausência de estruturas de participação nas quais alguém controla diretamente as ações de um grupo de pessoas em interação; tal controle, ao contrário, é muito presente no contexto escolar, e quase sempre centralizado na figura do professor. Nesse sentido, a participação nas interações obedecia a regras diferentes nesses dois contextos, o que provocava desentendimentos entre alunos e professores, e uma interpretação, por parte destes últimos, em termos de dificuldade ou resistência dos alunos à participação nas atividades escolares.

Erickson e Mohatt (1988), em uma detalhada análise microetnográfica da atuação de duas professoras de sucesso - uma nativa e outra branca - em classes de crianças indígenas, demonstraram que o fator decisivo para o desenvolvimento positivo das atividades não era o pertencimento étnico, mas a congruência entre o modo de condução das atividades pela professora, de forma mais ou menos sintonizada com o modo de trabalhar e interagir dos alunos. Segundo os autores, embora com diferenças na forma de organizar e conduzir as atividades, ambas possuíam um "estilo misto" quanto à maneira de interagir com os alunos, estilos desenvolvidos de forma que se buscasse congruência entre as exigências do contexto escolar e as características das interações nos contextos de vida cotidiana dos alunos.

A título de ilustração, pode-se citar ainda estudos que demonstram como muitos aspectos, comumente interpretados como existência de comunicação entre os sujeitos e centrais na forma de interagir como o encontro do olhar e as trocas verbais -, podem apresentar configurações diferentes, como no caso das mães e das crianças Mazahua estudadas por Paradise (1994), que, embora estejam em interação, não se olham e trocam pouquíssimas palavras, sem que isso signifique uma fragilidade, instabilidade ou mesmo ausência da situação interativa. Essa diferente configuração do contexto de interações foi definida pela pesquisadora como "separado-porém-junto" (separated-but-together), chamando a atenção para o 
fato de que era possível aferir a coordenação das ações entre mães e crianças, mesmo se os sinais verbais e não-verbais de que a interação acontecia não fossem imediatamente perceptíveis para um observador habituado a um outro padrão de comportamento.

Estudos nessa linha enfatizam as possibilidades de buscar uma organização das interações sociais na escola que sejam sensíveis aos padrões culturais das comunidades de origem dos alunos, e nesse sentido fala-se de uma "pedagogia culturalmente orientada", objetivando assim implementar as condições de sucesso acadêmico dos alunos pertencentes aos grupos minoritários.

A segunda linha, proposta de modo incisivo por Ogbu (1981, 1987, 1994, 1999), partia de uma abordagem metodológica por ele definida como macroetnográfica, e que identificou alguns dos limites da explicação fundamentada nas diferenças culturais, em função da evolução diferenciada que se verificava no processo de escolarização dos diversos grupos minoritários. Alguns desses grupos, com o passar das gerações, passavam de uma situação inicial de insucesso escolar para um quadro de progressiva melhoria do desempenho escolar de seus membros, chegando, em alguns casos, a obter resultados iguais ou melhores aos dos estudantes de grupos hegemônicos (como no caso de algumas minorias de origem asiática). Outros grupos, ao contrário, persistem em um quadro de dificuldades marcantes, mesmo apesar dos investimentos das famílias na educação dos próprios fillhos e dos programas especiais dirigidos ao atendimento das exigências específicas dos diferentes grupos. A questão de investigação que se torna central seria, então, a variabilidade do desempenho escolar entre diferentes grupos minoritários.

A proposta de Ogbu parte de uma leitura mais ampla da experiência histórica das minorias étnicas e leva em consideração o modo como estas interpretam a sua posição na sociedade em razão da experiência de contato com o grupo dominante, das oportunidades de inserção no mercado de trabalho e, enfim, dos contatos com as instituições geridas pelo grupo dominante, como a própria escola. A “epistemologia da comunidade" (Ogbu, 1981) sobre a escola, ou seja, o que a comunidade conhece sobre a escola, seria resultante do processo histórico de contato com o grupo dominante que detém a condução da instituição escolar. Nesse processo, a comunidade constrói um "quadro de referências culturais" (Ogbu, 1994), quadro esse que varia de grupo minoritário para outro. Esse quadro, considerado "diferenças culturais secundárias", orientaria a forma como os membros dessa comunidade agem e interpretam a própria presença na escola - podendo, então, favorecer ou dificultar a relação dos alunos com a escola. Assim, as diferenças culturais primárias seriam ressignificadas em função das orientações culturais que se originam no contato entre os grupos étnicos e os grupos dominantes. ${ }^{7}$ Segundo Ogbu (idem), algumas minorias, como no caso dos afro-americanos, desenvolveram um "quadro de referência opositivo" e uma "identidade social/coletiva opositiva", que traria dificuldades para a possibilidade de responder em sintonia com as modalidades requeridas nas escolas.

Não é minha intenção entrar na acirrada argumentação que foi desenvolvida entre os representantes dessas duas posições, uma vez que elas mesmas não são unívocas e possuem variações internas. De um lado, Ogbu (1999) insiste no fato de que a sua teoria tem um caráter explicativo, e que não é voltada diretamente para a intervenção, pois procura entender o papel desempenhado pelas "forças da comunidade" na maneira como os grupos minoritários se relacionam com a escola. Para Philips (1993), ${ }^{8}$ essa seria uma forma de “culpar as vítimas", uma vez que a pró-

\footnotetext{
7 Em sua teorização, Ogbu propõe uma tipologia para bus-
} car explicar as diferenças de desempenho entre as minorias étnicas, tipologia que não nos interessa aqui retomar, uma vez que é o foco de análise aquilo que busquei colocar em evidência.

8 Comentário presente na introdução à edição de 1993 de The invisible culture, na qual a autora alega que, em seu estudo sobre a "organização da comunicação nas interações face a face entre os indígenas de Warm Springs e de suas conseqüências para a organização das experiências de ensino e aprendizagem das crian- 
pria idéia de identidade opositiva seria a forma pela qual os professores atribuem sentido aos comportamentos dos alunos, e não uma orientação dos próprios alunos e de suas comunidades (p. xvii).

Como afirmado anteriormente, interessa-me colocar em evidência alguns aspectos da orientação teórica de ambas as posições, e de sua potenciais contribuições para a análise das experiências das escolas indígenas no Brasil. Particularmente, a abordagem que vem orientando as investigações sobre o processo de escolarização dos Xakriabá buscou articular elementos de uma e outra orientação, para atender às questões que emergiram no processo da pesquisa. ${ }^{9}$

\section{A história local da escolarização e a experiência dos professores xakriabás}

A terra indígena Xakriabá reúne uma população de mais de 6 mil habitantes, em uma área de aproximadamente 53 mil hectares. Situa-se no Noroeste do estado de Minas Gerais, no município de São João das Missões. O processo histórico de contato - que se pode verificar na origem mesma da área indígena, atestada no documento de doação de terras aos caboclos remanescentes da Missão de São João (Santos, 1997) - levou os Xakriabá a assumirem as modalidades características da região quanto às atividades de subsistência

ças indígenas dentro e fora da escola" (1993, p. xi) foi utilizada uma abordagem microetnográfica como parte de uma "abordagem etnográfica geral mais tradicional” (p. xiv), que envolvia observações em outros sítios, além da sala de aula.

9 Faz-se referência ao trabalho desenvolvido pelo grupo de pesquisa "Sujeitos socioculturais na educação indígena: uma investigação interdisciplinar", coordenado por mim junto com os colegas Carlos Henrique Souza Gerken, da Universidade Federal de São João Del-Rei (UFSJ), e Myriam Martins Álvares, da Pontifícia Universidade Católica de Minas Gerais (PUC-Minas). O grupo vem desenvolvendo suas atividades desde o ano 2000, e conta com financiamento da Fundação de Amparo à Pesquisa do Estado de Minas Gerais (FAPEMIG) e do Conselho Nacional de Desenvolvimento Científico e Tecnológico (CNPq). (são fundamentalmente pequenos agricultores e criadores de gado), em um processo, por um lado, de imposição cultural, que caracterizou os aldeamentos indígenas, e de intensa troca com outras populações, como os negros libertos no período após a escravidão.

A luta pela terra nas décadas de 1970 e de 1980 levou a população a dividir-se, permanecendo na reserva aqueles que escolheram a afirmação da própria ancestralidade indígena. Assiste-se assim a um processo crescente de reconstrução da identidade indígena, processo que tem estreita relação com a própria escola e que muito tem influenciado em suas dinâmicas. Atualmente a reserva tem 26 aldeias, com escolas em todas elas e ainda em três subaldeias, organizadas em duas unidades administrativas: a Escola Estadual Indígena Bukimuju (15 endereços, 56 turmas e 1.187 alunos) e a Escola Estadual Indígena Xukurank (14 endereços, 38 turmas e 840 alunos). São, atualmente (dados de 2003), 104 professores indígenas contratados pelo Estado, todos xakriabás, e a maioria atua na própria comunidade. Atualmente, contam com o atendimento de $1^{\mathrm{a}}$ à $4^{\mathrm{a}}$ série em todas as aldeias e de $5^{\text {a à }} 8^{\text {a }}$ série em sistema de nucleação, a diplomação da primeira turma tendo ocorrido em dezembro de 2003.

Já nas primeiras visitas a campo, procurando conhecer as escolas espalhadas por todo o território xakriabá, foi marcante a constatação inicial da existência de um contexto escolar onde se apresentava uma grande variedade de formas de organização das classes e de condução das atividades didáticas, seja no comportamento dos professores xakriabás, seja no comportamento dos próprios alunos. Apesar de apresentar também algumas características recorrentes, e que chamavam a atenção por especificidades que saltavam aos olhos - como o silêncio que reina em muitas das salas de aula, onde não se ouve a voz dos alunos e, em muitos casos, nem dos professores.

O início da pesquisa foi marcado pela idéia de um grupo cuja cultura era caracterizada pela oralidade e pelo escasso ou inexistente contato com a escrita, assim como pela novidade que a escola diferenciada trazia, ao estender o atendimento escolar a todas as 
crianças com professores das próprias aldeias. Além disso, existia a percepção, resultado de observações assistemáticas dentro do próprio PIEI-MG, de que as escolas xakriabás apresentavam uma modalidade de funcionamento mais "tradicional", se comparadas às propostas educacionais que eram veiculadas nas atividades de formação.

A primeira fase da pesquisa permitiu identificar a existência de um número significativo de escolas na região, que hoje é delimitada como território Xakriabá, na década que antecede a demarcação do território indígena, isto é, nos anos de 1970. Apesar da existência de um número insuficiente de escolas na região, nos relatos sobre a luta pela terra a educação escolar não aparece como tema relevante ou relacionado com as dinâmicas de posse do território (Leite, 2002).

Foi buscando compreender esse quadro contraditório - por um lado, a forma incisiva dos Xakriabá em implementar a escola indígena, valendo-se para isso das suas prerrogativas específicas; de outro, essa reprodução de aspectos de um contexto escolar que se assemelhava ao das demais escolas públicas da região que a pesquisa se orientou para a reconstrução da história local da escolarização. O quadro de referências culturais (Ogbu, 1994) que guiava a ação dos Xakriabá só poderia ser compreendido com base na história da relação desse povo com os grupos sociais dominantes com os quais se encontravam em contato. Além disso, tal reconstrução histórica não se poderia limitar às dinâmicas mais amplas, mas deveria chegar a explicitar o modo como a própria escola passou a fazer parte do contexto de vida da população local.

Foram assim identificadas algumas das professoras, que atualmente são contratadas como professoras indígenas, e que já atuavam como professoras anteriormente contratadas pela prefeitura local, algumas delas mesmo antes de $1987 .{ }^{10} \mathrm{Tal}$ fato direcionou

${ }^{10}$ Até 1996, era a Prefeitura de Itacarambi que respondia, como governo municipal, pelas relações com os Xakriabá. Com a criação do município de São João das Missões, em 1996, a refe- a primeira fase de entrevistas para esse grupo de professoras - que chamarei de "primeiras professoras". ${ }^{11}$

A reconstrução, ainda em processo, das experiências anteriores, permitiu verificar que os esforços da população local para buscar a instrução e a escola datam, no entanto, de bem antes. $\mathrm{O}$ registro mais antigo de uma escola na região, que consta na Prefeitura de Itacarambi, remonta à década de 1930. As experiências relatadas pelas "primeiras professoras" e por pessoas mais velhas da comunidade quanto ao próprio acesso à instrução segue um padrão recorrente nas zonas rurais: um pai de família que tivesse recursos econômicos contratava um professor, que vinha à sua casa ensinar a seus filhos. Na ocasião, freqüentemente se reuniam crianças da vizinhança e filhas de parentes, de modo que a atividade não era voltada somente para a família daquele que bancava o serviço. Entre outras características, a atividade dos professores não tinha uma longa continuidade no tempo, pois se tratava de profissionais que transitavam atendendo a diversas demandas. Como explicitado por uma ex-professora leiga, ${ }^{12}$ quando vinha o professor era necessário "pegar tudo o que podia, para ficar estudando depois". Em outros casos, a busca da instrução levava as famílias para fora da região. Ou ainda,

rência institucional passa a ser a administração do novo município. Cabe ressaltar o fato de que mais de $60 \%$ da população de São João das Missões é constituída pelos Xakriabá, assim como, até abril de 2003, o cacique Rodrigo era vice-prefeito, posto que deixou quando do seu prematuro falecimento. Em 2004, os Xakriabá venceram a eleição para a Prefeitura, que hoje tem à sua frente um dos diretores e professor indígena, José Nunes de Oliveira.

11 A expressão é tomada de Tassinari (2001), que enfatiza também a necessidade de analisar as experiências anteriores de escolarização. Cabe ressaltar, no entanto, que, como será discutido, essas mestras foram alunas de outros professores, alguns dos quais eram também membros das comunidades locais. Portanto, são "primeiras" em relação ao atual grupo de professores indígenas.

12 Trata-se de uma professora que exerceu a função até 1991, quando perdeu o cargo por não ter diploma de magistério. 
um membro alfabetizado podia ser ele próprio o alfabetizador dos demais. Poderíamos dizer que ainda não se tratava propriamente de escolarizar, uma vez que não existia a configuração de uma escola, mas de um grupo de crianças que eram instruídas por uma espécie de preceptor.

A documentação recolhida permitiu verificar que, em algumas das escolas existentes nos anos de 1970, mantidas pela Prefeitura como escolas rurais, os professores pertenciam à comunidade local. Das 28 escolas que compõem o documento "Relação das Escolas Rurais do Município de Itacarambi", ${ }^{13}$ treze situam-se em locais hoje pertencentes à área indígena.

Os anos de 1970 podem ser configurados como um segundo momento, quando a prefeitura local passa a responder às demandas que as comunidades apresentam. Segundo os depoimentos de pessoas que atuaram como professor na época, primeiro formava-se o grupo de alunos, decidia-se onde poderia funcionar a atividade escolar - quase sempre na casa de algum líder local, ou da própria professora ${ }^{14}$ - e a pessoa indicada como professora era apresentada à prefeitura local, com a lista de alunos, configurando uma demanda real. Em alguns casos, era aplicado um teste para

${ }^{13}$ Documento cedido pelo senhor Agenor, vereador em Itacarambi à época, que acompanhava o funcionamento das escolas. Junto à lista das escolas, encontravam-se duas cartas de professoras dirigidas a ele: uma que solicitava material ao mobral e outra que tratava da abertura de uma escola junto à Prefeitura de Itacarambi. O documento, segundo o senhor Agenor, refere-se ao período de 1973 a 1975. Em entrevista posterior realizada com o senhor Antônio Pereira de Souza, hoje pai de uma das professoras Xakriabá, foi identificado que algumas das escolas eram relacionadas com o MOBRAL (Movimento Brasileiro de Alfabetização). Dos nomes dos professores que constam do documento, três foram identificados pelo então diretor das escolas, José Nunes, como pessoas pertencentes à comunidade, todos professores leigos. Além do senhor Antônio, os outros dois professores são Geraldo Gonçalves dos Santos, tio de uma professora xakriabá, e Enita Pereira de Jesus, mãe de um professor.

${ }^{14} \mathrm{Na}$ fase atual, não podemos ainda analisar a variável gênero quanto à composição do quadro de professores nos diferen- verificar a qualificação; em outros, simplesmente era reconhecido a encargo à pessoa em virtude da demanda, e essa passava a ser remunerada pela prefeitura.

Esse mecanismo era utilizado pelas comunidades das aldeias, e foi descrito para várias aldeias da área Xakriabá, embora não possa ser estendido a todas elas. Podemos dizer que, nessa forma de contratação, a competência técnica e o comprometimento social do professor eram referidos a uma mesma matriz social, interna à comunidade das aldeias. Ou seja, a qualificação do professor era diretamente reconhecida por aqueles que "inscreviam" seus filhos na classe, e essa negociação face a face implicava um comprometimento direto do professor com os que o apoiavam ou a ele confiavam os próprios filhos. Essa forma de funcionamento, ao que parece, muito se aproximava das "escolas isoladas" que caracterizavam o ensino em Minas Gerais no início do século XX, embora convivesse e se articulasse, ou ainda, de alguma forma, se apoiasse na instituição estatal para a sua efetivação.

Em termos de atendimento à demanda escolar, podemos supor que tenha ocorrido um processo longo e lento, ao compararmos as informações contidas no documento dos anos de 1970 e aquelas presentes no diagnóstico realizado em 1995, quando da criação do PIEI-MG. O que revela o diagnóstico, em período de plena legalidade das terras indígenas, é que nela existem doze escolas municipais de $1^{\mathrm{a}}$ à $4^{\mathrm{a}}$ série (quase a mesma quantidade dos anos de 1970), com 17 professores, 14 contratados pela Prefeitura de Itacarambi e três pela FUNAI. Entre esses, apenas quatro pertencem à comunidade local, e eram, na época, professores leigos (Minas Gerais, 1995). Em 1997, dez anos após a homologação do território, quando a primeira turma de professores indígenas se encontrava no segundo ano do Curso de Formação de Professores indígenas realizado pelo PIEI-MG, foram criadas

tes momentos da história local da escolarização. Cabe registrar, porém, um aumento da presença masculina desde 1997, com a implantação da escola pública indígena. 
as escolas estaduais indígenas e os alunos-professores assumiram imediatamente seus cargos.

Dois aspectos devem ser ressaltados, pois se tornam importantes para a compreensão da situação atual das escolas e da forma como a população xakriabá, as lideranças indígenas e os próprios professores comportam-se quanto às necessidades educacionais e à sua implementação. Em primeiro lugar, a ausência ou a distância do aparato estatal, que durante muito tempo gerou um espaço de atuação livre das comunidades quanto à gestão da demanda por escolas e ao seu próprio funcionamento. O que se conseguiu nos anos anteriores a 1997, pode-se dizer, de maneira geral, foi resultado de uma ação direta das comunidades das aldeias no sentido de prover as necessidades educacionais. Em contrapartida, o fato de a maioria dos professores não pertencer às comunidades das aldeias foi indicado, no documento diagnóstico (idem), como fator que comprometia o adequado funcionamento das escolas. De fato, entre os problemas registrados em 1992 em documentação da 9a Delegacia Regional de Ensino (Januária), a falta de alojamento para os professores e problemas com "recursos humanos" constam do quadro de informações de várias escolas.

Em segundo lugar, é importante atentar para o caráter não-compulsório da escolarização, que perdurou por muito tempo, dadas as condições precárias de funcionamento, com um número de classes sempre inferior à demanda. Apesar da imprecisão das informações disponíveis, para se ter uma idéia, em 1992 são 561 alunos inscritos; à época do diagnóstico, as lideranças locais afirmam a existência de cerca de 500 crianças sem escolas (idem), ou seja, uma demanda latente de quase o dobro de alunos. Nos dois primeiros anos de funcionamento das escolas estaduais indígenas, os alunos inscritos eram cerca de 1.300. Ou seja, no período anterior, podemos dizer que a escolarização terminava por ser requerida e implementada por aqueles que por ela se interessavam.

Como se pode ver, a instituição da escola indígena trouxe profundas alterações. A experiência anterior dos Xakriabá, que podemos descrever como uma gestão comunitária informal, encontra eco nas pro- postas do PIEI-MG, que se inscrevem no quadro da criação de escolas diferenciadas, caracterizadas também enquanto escolas comunitárias, de acordo com o RCNEI de 1998. Com o início do funcionamento das escolas estaduais indígenas, o que antes era um problema de gestão de relações com a prefeitura local relações marcadas pelo conflito e pela distância das instâncias de decisão - passa então a ser administrado em uma situação de estreito contato com o Estado. Surge um novo componente na gestão das demandas educacionais: essa era, até então, realizada diretamente pelas comunidades das diferentes aldeias (e provavelmente por isso não aparece nos relatos e análises sobre as dinâmicas de posse da terra), e passa agora a ser mediada pela instância comunitária mais ampla, o povo indígena Xakriabá, cujas lideranças passam a ter acesso direto à Secretaria de Estado de Educação (SEE) de Minas Gerais, por sua participação na coordenação do PIEI-MG. Se, por um lado, nessa nova configuração a comunidade indígena passa a exercer uma maior influência sobre as decisões acerca das suas escolas, por outro lado, tal influência se dá no quadro de uma maior proximidade com o aparato estatal e com suas formas características de gestão e controle das instituições públicas. Em outras palavras, um aparato de gestão estatal que, em princípio, não vem ao encontro dos dois componentes que se orientam em direção à gestão comunitária, a menos que seja realizada uma ação contínua de mediação.

Além da dimensão da gestão, o fato de a expansão da escolarização ter ocorrido muito recentemente fez com que passassem a conviver formas muito diferentes de organização pedagógica das escolas, de condução das atividades didáticas, e mesmo formas diferentes nas relações com os pais e com a comunidade. Para melhor compreender esse panorama variado de contextos escolares - ou, ainda, para descrever e analisar as diferentes culturas escolares presentes entre os Xakriabá - foi necessário realizar observações em classe, e tomou-se como referência inicial as classes das primeiras professoras. As descrições resultantes dessas observações foram então analisadas tendo como pano de fundo as referências que as pró- 
prias professoras haviam apresentado, quando, nas entrevistas, abordaram sua experiência como alunas e profissionais. As escolhas pedagógicas, assim como alguns aspectos da forma como as professoras interagiam com seus alunos ganharam um significado diferente quando confrontados com a sua experiência e referidos ao processo mais amplo de escolarização pelo qual passaram as comunidades das aldeias xakriabás.

A título de ilustração, serão discutidos dois exemplos significativos que nos permitem analisar alguns aspectos da cultura escolar que está se configurando entre os Xakriabá, aspectos que podem ser mais bem explorados e compreendidos à luz das discussões sobre as descontinuidades culturais, ou seja, sobre os diferentes modelos culturais que informam a prática de professores e alunos xakriabás.

O primeiro exemplo refere-se à presença em classe dos assim chamados "encostados", ou seja, das crianças em idade inferior à idade de cursar o ensino fundamental, e que, apesar de oficialmente não estarem inscritas, passam a freqüentar as salas de aula em companhia de seus irmãos e/ou primos maiores. A presença dos "encostados" permite que se recrie, no interior das classes escolares, situações semelhantes àquelas existentes no contexto de vida cotidiana das crianças, quando essas podem participar das diferentes atividades desenvolvidas na comunidade. Em tais situações, as crianças observam e interagem com as atividades dos adultos e das crianças maiores, sem que seja delas esperado uma participação plena, no sentido de contribuir efetivamente para a tarefa que está sendo realizada. Tal modelo foi verificado em outros grupos (Cohn, 2002; Pereira, 1999), e é descrito como um contexto de aprendizagem no qual não existe uma separação entre "o fazer e o aprender", ou seja, no qual as situações de aprendizagem são as atividades desenvolvidas na vida cotidiana, não existindo uma configuração específica para o momento do ensinar-aprender. É a própria criança que se envolve nas atividades rotineiras e busca as formas de interagir e participar que lhe parecem mais atender ao seu interesse, sendo que essa participação é acolhida pelos adultos, sem que estes, por sua vez, interrompam a atividade que estão desenvolvendo. ${ }^{15}$

A presença dos "encostados" parece seguir esse padrão, adaptando-se, porém, ao contexto escolar: as crianças menores participam de algumas das atividades sem que pese sobre elas as exigências de desempenho a que as demais crianças devem responder. $\mathrm{O}$ que pode parecer um simples e banal exercício de imitação dos irmãos funciona, na verdade, como um contexto de aprendizagem que favorece a participação da criança em seu ritmo e suas modalidades próprias, alternando longos momentos de curiosa e atenta observação com momentos de tentativas de execução de tarefas e de apropriação dos instrumentos, simbólicos e práticos, de participação no contexto escolar. Tanto mais importante é essa participação em razão da escassa experiência de escolarização presente nas comunidades e da necessidade de realizar uma socialização inicial das crianças quanto às particularidades do contexto escolar - que mantém algumas demarcações que o tornam explicitamente distinto dos demais contextos sociais, mesmo quando assume características locais (Duranti, 1992).

No início, a presença dos "encostados" foi motivo de controvérsias com a SEE, pois os recursos repassados para as escolas eram calculados levando em conta somente os inscritos oficialmente, o que provocava, quanto à merenda, por exemplo, dificuldades permanentes de fornecimento suficiente para todas as crianças. Com o passar do tempo, e com as pressões exercidas pelos próprios Xakriabá, a presença dos "encostados" foi integrada ao funcionamento regular das escolas. Se por um lado isso garante a especificidade da experiência, por outro tal presença corre o risco de ser interpretada somente como um fator de pressão em direção à abertura de escolas infantis. A proposta de abertura das escolas infantis, já presente na comunidade e entre os professores, é interpretada pelos agentes institucionais

15 Para uma descrição detalhada do contexto de aprendizagem na vida cotidiana entre os Xakriabá, ver Pereira (2003). 
como parte de um percurso "adequado" de escolarização (e, mais ainda, como um dos direitos a serem garantidos). A possibilidade de criar-se contextos escolares que sejam "culturalmente orientados" respondendo assim à proposta de uma educação escolar diferenciada - choca-se assim com uma versão consolidada do que seja a escola, incluindo sua lógica de separação por grupos de idade e da especificidade mesma do espaço de aprendizagem em relação aos demais contextos sociais.

Outro exemplo significativo vem da experiência de uma das primeiras professoras, que realizava "reprovações" dos melhores alunos nas séries iniciais para que estes permanecessem na classe de principiantes e funcionassem como apoio para o processo de alfabetização deles. O procedimento é aceito pelos alunos e pais, e cria uma diferente orientação para a presença em classe - na qual as crianças passam a se ocupar de algo que não somente o próprio processo de aprendizagem, pois são efetivamente envolvidas nas atividades de aprendizagem de outros colegas - e para a experiência dos próprios alunos aparentemente "retidos", que, ao serem aprovados no ano seguinte para uma classe mais avançada, vivenciam um percurso que desmistifica a lógica por etapas fixas que na maioria das vezes caracteriza a experiência escolar. O individualismo que caracteriza a experiência escolar e a idéia de uma progressão linear da aprendizagem são assim concretamente deslocados em favor de uma experiência que apresenta diferentes facetas e diferentes dimensões da convivência e da possibilidade de aprender dentro da escola.

\section{Conclusões}

As descrições de diferentes contextos escolares que as investigações sobre as descontinuidades culturais tornaram possíveis de serem conhecidas introduzem elementos novos na forma de considerar aspectos da experiência escolar - como a presença dos "encostados" ou a "reprovação dos melhores". Esses estudos alertam-nos para a necessidade de passar a perceber também como elementos culturais aqueles aspectos da vida cotidiana - como as modalidades de interação verbais e não-verbais e as relações de autoridade - que estão profundamente enraizados na próprio corpo, nos modos de ser e de conviver dos diferentes grupos indígenas, e que não alcançam visibilidade ou o estatuto de aspectos "culturais", e que muitas vezes, por isso mesmo, ficam relegados a aspectos pedagógicos a serem manipulados em função de exigências didáticas de eficiência do processo de aprendizagem. Pode-se afirmar que a "cultura invisível" de que trata Philips (1993) responde pela especificidade da experiência escolar dos Xakriabá, um povo que deve continuar lutando para a legitimação da própria identidade, e que se vê na constrição de elaborar formas de torná-la pública que respondam aos estereótipos do que é considerado uma "autêntica cultura indígena". A facilidade com que hoje, nas diferentes classes xakriabás, é possível acolher crianças de diferentes idades e que participam de modo diferenciado das atividades escolares - uma característica difícil de encontrar em escolas do meio urbano - pode ser considerada contemporaneamente uma característica do contexto escolar e um recurso cultural do mais alto potencial pedagógico. Recurso potencial que pode desaparecer em pouco mais de duas gerações, se a configuração do contexto escolar não tornar mais possível a sua concreta ativação.

No entanto, a forma como a "cultura invisível" será ativada e significada dependerá em grande parte das "forças da comunidade", ou seja, da forma como os Xakriabá interpretam a própria experiência escolar e o sentido que atribuirão à escola no processo de afirmação da própria identidade e da busca de garantias quanto ao direito à escola diferenciada.

\section{Referências bibliográficas}

COHN, Clarice. A criança, o aprendizado e a socialização na antropologia. In: LOPES DA SILVA, Aracy; MACEDO, Ana Vera Lopes de; NUNES, Ângela (Orgs.). Criança indígena; ensaios antropológicos. São Paulo: Global/MARI-USP/FAPESP, 2002. p. 213-235. DURANTI, Alessandro. Linguaggio, azione e concetto del sé: gli effetti della scolarizzazione. In: Etnografia del 
parlare quotidiano. Roma: La Nuova Italia Scientifica, 1992. p. 119-138.

EMIHOVICH, Catherine. Continuità e discontinuità culturale in educazione. In: GOBBO, Francesca (Org.). Antropologia dell'educazione. Scuola, cultura, educazione nella società multiculturale. Milano: Unicopli, 1996. p. 85-104.

ERICKSON, Frederick; MOHATT, Gerald. Cultural organization of participation structures in two classrooms of Indian students. In: SPINDLER, George; SPINDLER, Louise (Eds.). Doing the ethnography of schooling: educational anthropology in action. Prospect Heights: Waveland Press Inc., 1988. p. 132-174.

GIBSON, Magareth. Ethnicity and school performance: complicating the immigrant/involuntart minority typology. Anthropology \& Education Quarterly, Issues in School Ethnography, v. 28, n. 3, p. 3-29, 1997.

GOMES, Ana Maria. R. A configuração das classes nas escolas indígenas Xakriabá: uma análise preliminar da experiência dos professores. In: ENCONTRO INTERNACIONAL LINGUAGEM, CULTURA E COGNIÇÃO, 2., 2003, Belo Horizonte. Anais... Belo Horizonte: Faculdade de Educação da UFMG, $2003 a$.

. O processo de escolarização dos Xakriabá: história local e a proposta de educação escolar diferenciada. In: REUNIÃO DE ANTROPOLOGIA DO MERCOSUL, 5., 2003, Florianópolis. Anais.V RAM: Antropologia em Perspectivas. Florianópolis: Programa de Pós-Graduação em Antropologia Social (PPGAS)/UFSC, 2003b.

JACOB, Evelyn; JORDAN, Catherin. Explaining school performance of minority students. Anthropology \& Education Quarterly, Theme Issue, v. 18, n. 4, 1987.

LEITE, Lúcia H. Alvarez. Escuela, movimientos sociales y ciudadanía. Tese (Doutorado em Educação) - Facultad de Filosofía e Ciencias de la Educación, Universidad de Valencia, 2002.

LENZI-GRILLINI, Filippo; CASTRO, Maria Gontijo; GOMES, Ana Maria R. La scuola fra gli Xakriabá: tra sviulppo economico ed innovazione didattica. Antropologia, n. 4, p. 95-116, 2004.

MINAS GERAIS. Secretaria de Estado de Educação. Implantação das escolas indígenas/MG. Diagnóstico da Situação Educacional nas Áreas Indígenas/MG. Superintendência de Desenvolvimento do Ensino/Diretoria de Desenvolvimento Curricular, SEE/ MG, 1995 (Elaboração de Myriam Martins Álvares).

OGBU, John. School ethnography: a multilevel approach. Anthropology \& Education Quarterly, Issues in School Ethnography, v. XII, n. 1, p. 3-29, 1981.
. Variability in minority school performance: a problem in search of explanation. Anthropology \& Education Quarterly, v. 18, n. 4, p. 312-334, 1987.

From cultural differences to differences in cultural frames of reference. In: GREENFIELD, Patricia M.; COCKING, Rodney R. (Eds.). Cross-cultural roots of minority child development. Hillsdale: Lawrence Erlbaum, 1994. p. 365-391.

. L'antropologia dell'educazione: introduzione e cenni storico-teorici. In: GOBBO, Francesca (Org.). Antropologia dell'educazione. Scuola, cultura, educazione nella società multiculturale. Milano: Unicopli, 1996. p. 1-47.

. Una teoria ecológico-culturale sul rendimento scolastico delle minoranze. Etnosistemi, Roma: CISU, n. 6, p. 1120, 1999.

PARADISE, Ruth. Interactional style and non-verbal meaning: Mazahua children learning how to be separate-but-together. Anthropology \&Education Quarterly, v. 25, n. 4, p. 156-171, 1994. PEREIRA, Ângela Maria Nunes Machado. A sociedade das crianças A'uwae-Xavante: por uma antropologia da criança. Lisboa: Instituto de Inovação Educacional, 1999 (Temas de Investigação, 8). PEREIRA, Verônica Mendes. Cultura escolar ou escolarização da cultura? Um olhar sobre as práticas culturais dos índios Xakriabá. Dissertação (Mestrado em Educação) - Faculdade de Educação, Universidade Federal de Minas Gerais, 2003.

PHILIPS, Susan. The invisible culture: communication in classroom and community on the Warm Springs Indian Reservation. Prospect Heights: Waveland Press, 1993 (1. ed. 1983).

POVEDA, David. La educacion de las minorias etnicas desde el marco de las continuidades-discontinuidades família-escuela. Gazeta de Antropología, n. 17, p. 17-31, 2001.

ROCKWELL, Elsie. La dinámica cultural en la escuela. In: GIGANTE, Elba (Coord.) Cultura y escuela: la reflexión actual en México. México: Conaculta, 1992 (Serie Pensar la Cultura) (mimeo).

SANTOS, Ana Flávia Moreira Do terreno dos caboclos do Sr. São João à terra indígena Xakriabá: as circunstâncias da formação de um povo. Um estudo sobre a construção social de fronteiras. Dissertação (Mestrado em Antropologia) - Departamento de Antropologia, Universidade de Brasília, 1997.

SILVA, Aracy Lopes da. Uma "antropologia da educação" no Brasil? Reflexões a partir da escolarização indígena. In: SILVA, Aracy Lopes da; FERREIRA, Mariana Kawall Leal (Orgs.). Antropolo- 


\section{O processo de escolarização entre os Xakriabá}

gia, história e educação: a questão indígena e a escola. São Paulo: Global/FAPESP/MARI, 2001. p. 29-43.

TASSINARI, Antonella. Escola indígena: novos horizontes teóricos, novas fronteiras de educação. In: SILVA, Aracy Lopes da; FERREIRA, Mariana Kawall Leal (Orgs.). Antropologia, história e educação: a questão indígena e a escola. São Paulo: Global/ FAPESP/MARI, 2001. p. 44-70.

ANA MARIA R. GOMES, doutora em educação pela Università degli Studi di Bologna, é professora da Faculdade de Educação da Universidade Federal de Minas Gerais (UFMG). Principais publicações: Vegna che ta fago scriver: Etnografia della scolarizzazione in una comunità di Sinti (Roma: CISU, 1999);
Etnografia nei contesti educativi (organizado com Francesca Gobbo, Roma: CISU, 2003); Della scuola e della scolarizzazione (Antropologia, Milano: Meltemi, anno IV, n. 4, p. 163-174, 2004); El proceso de escolarizacion de los Xakriaba: historia local y rumbos de la propuesta de educacion escolar diferenciada (Cuadernos de Antropologia Social, Argentina: Universidad Buenos Aires, n. 19, p. 29-48, 2004). Pesquisa em andamento: "Sujeitos socioculturais na educação indígena em Minas Gerais" (Conselho Nacional de Desenvolvimento Científico e Tecnológico - CNPq/ Fundação de Amparo à Pesquisa do Estado de Minas Gerais - FAPEMIG).E-mail: anagomes.bhz@terra.com.br

Recebido em novembro de 2004 Aprovado em abril de 2005 
Las transformaciones en la esfera pública y acción ecológica: educación y política en tiempos de crisis de la modernidad

Discute las transformaciones de la esfera pública contemporanea y la emergencia de nuevos modos de acción política asociados a la formación de un campo político y pedagógico ambiental. Afirma que la acción politica ambiental, en el contexto del ambientalismo y de la nueva izquierda contracultural. puede ser considerada una de las expresiones de la crisis de la modernidad. En este sentido, los movimientos ecológicos buscan reposicionar el ego y el socius, el privado y el público, la ética y la estética en la esfera de acción social. Esto repone un dilema que remite tanto a las tendencias conflictivas de la modernidad cuanto a su proyecto emancipatorio. Frente a esa problemática, algunos análisis destacan la disolución y el declinio de la política, en cuanto otros enfatizan la emergencia de una nueva forma de acción politica. Por fin, el artículo explora los rebatimientos de esos cambios sociales en el campo de la acción educativa, particularmente la educación ambiental, preocupada con la construcción de un sujeto ecológico. Palabras claves: acción politic; modernidad; educación ambienta; sujeto ecológico

\section{Ana Maria R. Gomes}

O processo de escolarização entre os Xakriabá: explorando alternativas de análise na antropologia da educação

A criação das escolas estaduais indígenas, pelo Programa de Implantação das Escolas Indígenas de Minas Gerais (PIEI-MG), em 1997, foi um fato marcante para todos os povos envolvidos. Entre os Xakriabá, o processo de escolarização teve seu início pelo menos vinte anos antes, e foi intensificado de modo muito acelerado com o início do funcionamento das escolas estaduais indígenas. Tal expansão acelerada gerou um contexto escolar com características muito peculiares. No artigo busca-se explorar algumas perspectivas de análise sobre os processos de escolarização, propostas pela antropologia da educação. A presença dos "encostados" ou a possibilidade de "reprovação dos melhores", dois exemplos de aspectos que caracterizam as escolas xakriabás, alertam-nos para a necessidade de se passar a perceber também como elementos culturais os aspectos da vida cotidiana (como as modalidades de interação verbais e não-verbais e as relações de autoridade) que não alcançam imediata visibilidade, e não são, portanto, considerados parte da especificidade cultural que marca a escola xakriabá.

Palavras-chave: educação indígena; cultura escolar; antropologia da educação

The process of schooling among the Xakriabá people: an exploration of alternative forms of analysis in the anthropology of education

The creation of indigenous public schools in 1997 by means of the Programme for the Implantation of Indigenous Schools in the State of Minas Gerais (PIEI-MG) was an important event for all the indigenous groups involved. Among the Xakriabá people, the process of schooling began twenty years earlier, and was intensified by the creation of the indigenous public schools. This accelerated expansion generated a very specific school context. In this article, explore the different perspectives of analysis of the schooling process proposed by the anthropology of education. Two examples of the characteristics of the xakriabá schools - the attendance of non official students, the "indolent", and the possibility of failing the best students - focus our attention on those aspects of daily life that are not generally perceived as cultural elements (such as the verbal and non verbal interactional styles and the relations of authority). These aspects are not immediately visible and are not, therefore, taken as constitutive of the cultural specificity of the xakriabá school.

Key-words: indigenous education; school culture; anthropology of education

El proceso de escolaridad entre los Xakriabás: explorando alternativas de análisis en la antropología de la educación

La creación de las escuelas estatales indigenas, através del Programa de Implantación de las Escuelas Indígenas de Minas Gerais (PIEI-MG) en 1997, fue un hecho marcante para todos los pueblos envueltos. Entre los Xakriabás, el proceso de escolaridad tuvo su inicio por lo menos veinte años antes, y fue intensificado de un modo muy acelerado, con el inicio del funcionamiento de las escuelas estatales indígenas. La expansión acelerada produjo un contexto escolar con características muy peculiares. En el articulo explorar algunas perspectivas de análisis al respecto de los procesos de escolaridad, propuestas por la antropología de la educación. La presencia de los "arrimados" o la posibilidad de "reprobación de los mejores", son dos aspectos que caracterizan a la escuela xakriabá, poniéndonos sobre aviso para la necesidad de pasar a notar, también, como elementos culturales, los aspectos de la vida cotidiana (como las modalidades de interacción verbal y noverbal y las relaciones de autoridad) que no alcanzan una inmediata visibilidad, y no son, por lo tanto, considerados como parte de la 
especialidad cultural, que marca a la escuela xakriabá.

Palabras claves: educación indígena; cultura escolar; antropología de la educación

Francisco José Calazans Falcon

\section{História cultural e história da} educação

$\mathrm{O}$ artigo analisa a separação entre a história cultural e a história da educação. Examinando obras a partir dos anos de 1970, verifica a importância crescente da história cultural e a ausência quase completa de trabalhos relativos à história cultural da educação. Aborda questões disciplinares e institucionais, mas também historiográficas, que concorrem para a exclusão de determinadas disciplinas, como a história da educação, do âmbito de trabalho do historiador. Durante a década de 1980, detecta maior interesse pela história da educação e por sua inserção nas perspectivas historiográficas. Focaliza algumas questões que interessam aos historiadores e aos historiadores da educação: as relações entre história e cultura; a tentativa de considerar a história cultural em duas perspectivas: uma que lhe atribui o recorte e análise de objetos culturais, e outra que privilegia os pressupostos metodológicos, abordando tanto as práticas sociais como as suas representações, de acordo com concepções das diversas teorias sociais. Conclui que a história cultural é um campo multi ou interdisciplinar, não apenas um tipo de abordagem, nem apenas um novo espaço ou dimensão do real, e enfatiza a necessidade de uma reflexão mais sistemática sobre a educação como um tema/objeto de investigação necessário à compreensão da formação cultural de uma sociedade.

Palavras-chave: história cultural; história da educação

\section{Cultural history and the history of education}

The article analyses the separation between cultural history and the history of education. It verifies the growing importance of cultural history and the almost complete absence of studies on the cultural history of education based on an examination of works starting in the 1970s. It deals with disciplinary, institutional and historiographic questions which contribute to the exclusion of determined subject areas like the history of education in the ambit of work of the historian. It detects a greater interest in the history of education during the 1980s, and in its insertion in historiographic perspectives. It focuses on some questions which are of interest to historians and historians of education: the relation between history and culture; the attempt to consider cultural history from two perspectives - one which attributes to it the separation and analysis of cultural objects and the other which privileges methodological presuppositions dealing with both social practices and their representations, in accordance with conceptions from diverse social theories. It concludes that cultural history is a multi or interdisciplinary field, not simply a kind of approach nor a new space or dimension of reality and emphasizes the need for a more systematic reflection on education as a theme/object of investigation necessary for understanding the cultural formation of a society.

Key-words: cultural history; history of education

\section{Historia cultural y historia de la educación}

El artículo analiza la separación entre la historia cultural y la historia de la educación. Examinando obras a partir de los años de 1970, se verifica la importancia creciente de la historia cultural y la ausencia casi completa de trabajos relativos a la historia cultural de la educación. Aborda cuestiones disciplinares e institucionales, pero también historiográficas, que concurren para la exclusión de determinadas disciplinas, como la historia de la educación, del ámbito de trabajo del historiador. Durante la década de 1980, detecta un mayor interés por la historia de la educación y por su inserción en las perspectivas historiográficas. Focaliza algunas cuestiones que interesan a los historiadores y a los historiadores de la educación; las relaciones entre historia y cultura; la tentativa de considerar la historia cultural bajo dos perspectivas; una que le atribuye el recorte y análisis de objetos culturales, y otra que privilegia los presupuestos metodológicos, abordando tanto las prácticas sociales como sus presentaciones, de acuerdo con concepciones de las diversas teorias sociales. Concluye que la historia cultural es un campo multi o interdisciplinar, no apenas un tipo de abordage, ni apenas un nuevo espacio o dimensión de lo real, y enfatiza la necesidad de una reflexión más sistemática sobre la educación como un tema/objeto de investigación necesario a la comprensión de la formación cultural de una sociedad.

Palabras claves: historia cultural; historia de la educación

\section{Luiz Felipe Baêta Neves}

\section{História intelectual e história da educação}

O texto começa por tratar do uso anacrônico de palavras e idéias. Tal uso caracteriza-se por uma rigidez na interpretação da linguagem, que acaba por se fixar nos significados correntes na época em que se escreve a história. Essa reificação do discurso tende a desconsiderar as possíveis significações 